\title{
Extrafiscalidade ambiental - o estado do conhecimento no Brasil
}

\section{Environmental extrafiscality - the state of knowledge in Brazil}

William Thiago de Moraes - Mestrado em Sustentabilidade na Gestão Ambiental, pela Universidade Federal de São Carlos (UFSCar). Docente dos cursos de pós-graduação da Fundação Herminio Ometto (FHO/Uniararas) e de graduação da Escola Superior de Administração, Marketing e Comunicação (ESAMC).E-mail: william.moraess@gmail.com.

Fernanda Sola - Doutora em Ciência Ambiental, pela Universidade de São Paulo (USP). Docente do Programa de Pós-Graduação de Sustentabilidade na Gestão Ambiental na Universidade Federal de São Carlos (PPGSGA/UFSCar).E-mail: sollafernanda@gmail.com.

\section{Resumo}

O objetivo deste estudo é buscar o "estado da arte" a respeito da extrafiscalidade ambiental no Brasil, o que se justifica pelo contínuo aumento de mudanças nas legislações tributárias visando a tutela do meio ambiente por meio da tributação, assunto este que ainda encontra pequena difusão em âmbito nacional. Tomou-se como mecanismo de seleção de artigos, as publicações da última década em periódicos classificados pela Capes, que versaram sobre a intervenção do Estado com o emprego de instrumentos extrafiscais, de caráter nitidamente ambiental e inventariou 26 artigos publicados em 23 periódicos. Concluiu-se que a tributação poderá ter conotação ambiental, voltada à proteção e promoção do direito social ao meio ambiente ecologicamente equilibrado, por meio da aplicação da extrafiscalidade ambiental, não só com a majoração de tributos para aquelas atividades ambientalmente nocivas, mas também com o emprego de incentivos fiscais, como forma indutora do comportamento dos particulares em prol da proteção ambiental.

\section{Palavra-chave}

Tributação. Intervenção na Economia. Extrafiscalidade. Extrafiscalidade Ambiental.

\begin{abstract}
The objective of this study is to pursue the "state of the art" regarding environmental extrafiscality in Brazil, which is justified by the ongoing increase of the tax reforms. These addresses the environmental protection through taxation, a subject is not widespread in the national scope. The publications of the last decade were used as selection mechanism for papers published by Capes, which dealt with the intervention of the State with the use of extra-fiscal environmental instruments and registered 26 articles published in 23 journals. It was concluded that the taxation could have an eminently environmental meaning, related to at the protection and promotion of the social right to the ecologically balanced environment, through the application of environmental extrafiscality. This view of extrafiscality can be adopted for the taxation in different ways, not only with the increase of taxes for those environmental threats, but also with the use of tax incentives, as an inducing way of the behavior of private individuals in favor of environmental protection.
\end{abstract}

\section{Keywords}

Taxation. Intervention in the Economy. Extrafiscality. Environmental Extrafiscality. 


\section{INTRODUÇÃO}

O Estado Brasileiro foi revestido pela Constituição Federal do Poder de Tributar para prover recursos aos cofres públicos com a finalidade de proporcionar o bem comum ao povo e o alcance dos preceitos e mandamentos constitucionais (BRASIL, [1988] 2016).

A Carta Magna também possibilitou ao Estado a utilização do sistema tributário para finalidades diversas da mera arrecadação de recursos financeiros (BRASIL, [1988] 2016) por intermédio da extrafiscalidade tributária, como instrumento inibidor ou fomentador de comportamentos (BLANCHET; OLIVEIRA, 2014).

A tributação extrafiscal lastreia-se em objetivos específicos, possibilitando ao Estado a intervenção em determinadas áreas, como na economia, para a consecução de seus objetivos fundantes, sem intentar obter recursos financeiros, apenas estimular ou reprimir determinadas condutas (CARVALHO, 2013).

A defesa e a preservação do meio ambiente ecologicamente equilibrado são deveres do Estado e direito fundamental assegurado constitucionalmente a todos os indivíduos, inclusive às futuras gerações (BRASIL, [1988] 2016).

Diante disso, questiona-se a possibilidade de o sistema tributário ser capaz de absorver este dever constitucional e dar origem a incentivos fiscais ou a majoração da carga tributária para comportamentos ambientalmente protetivos ou nocivos, em prol da proteção do meio ambiente, por intermédio da extrafiscalidade ambiental.

Isso se justifica pelo crescente aumento de alterações nas legislações tributárias visando à tutela do meio ambiente por meio da tributação, assunto que, em âmbito nacional, encontra pequena difusão, bem como estudos ainda embrionários, evidenciando a necessidade do desenvolvimento de pesquisas na área e da elucidação desse fenômeno jurídico-tributário (ALBUQUERQUE, 2003).

Para tanto, objetivou-se consolidar as abordagens realizadas pela produção científica nacional a respeito da extrafiscalidade ambiental, sua dimensão e aspectos, para constatar o estado do conhecimento atual sobre o tema.

Objetivando alcançar este desígnio, buscou-se ainda sedimentar as definições conceituais de "extrafiscalidade tributária" e "extrafiscalidade ambiental", termos que foram elementos de buscas integradas nos repositórios institucionais sobre produção científica e artigos publicados na última década em periódicos classificados pela Coordenação de Aperfeiçoamento de Pessoal de Nível Superior (Capes). 
Outrossim, estruturados os resultados, buscou-se analisar as discussões sobre a extrafiscalidade ambiental e seus avanços na legislação brasileira, para, por fim, responder se há congruência constitucional entre o dever estatal de proteção ambiental com o sistema tributário nacional; questionamento este que se almejou comprovar com uma resposta afirmativa, de modo a criar subsídios à adoção de políticas tributárias pautadas na proteção do meio ambiente, por meio da extrafiscalidade tributária.

\section{TRIBUTAÇÃO E INTERVENÇÃO DO ESTADO NA ECONOMIA}

O Estado tem como finalidade a consecução do bem comum - conjunto de necessidades gerais da coletividade, essenciais a um existir digno - (SILVA, 2006) e, para tanto, a Constituição Federal atribuiu-lhe poderes para viabilizar seus objetivos fundamentais ${ }^{1}$, dentre eles, o Poder de Tributar, que dota o Estado de instrumentos para obter recursos financeiros indispensáveis a esta missão.

Como qualquer poder estatal, este não é irrestrito ou livre de amarras, pois se o fosse seria suscetível ao cometimento de abusos, e coube à Constituição Federal estabelecer limitações a seu exercício, mediante a enunciação de princípios constitucionais da tributação (SILVA, 2006). Esses princípios restringem a invasão estatal ao patrimônio particular dos contribuintes, quando, por meio de tributos, busca arrecadar recursos para viabilizar sua função principal de provedor das necessidades coletivas.

O exercício do poder de tributar perpassa a simples finalidade arrecadatória de recursos financeiros aos cofres públicos, podendo a tributação ser utilizada como instrumento de política pública para atingir diferentes desígnios, voltados à promoção de interesses sociais, políticos ou econômicos. Hipótese em que a tributação terá finalidade diversa da meramente fiscal - arrecadatória de recursos e ganhará caráter extrafiscal, com o fim de (re)ordenar a economia e as relações sociais (SABBAG, 2014).

A doutrina clássica firmou o entendimento de que o Estado pode agir como agente normativo e regulador em sua atuação interventiva no domínio econômico, com o objetivo de exercer as funções de fiscalização, incentivo e planejamento da atividade econômica (SABBAG, 2014, p. 163), o que o faz consubstanciado no artigo 174 da Constituição Federal.

\footnotetext{
"Art. $3^{\circ}$ Constituem objetivos fundamentais da República Federativa do Brasil: I - construir uma sociedade livre, justa e solidária; II - garantir o desenvolvimento nacional; III - erradicar a pobreza e a marginalização e reduzir as desigualdades sociais e regionais; IV - promover o bem de todos, sem preconceitos de origem, raça, sexo, cor, idade e quaisquer outras formas de discriminação" (BRASIL, [1988] 2016, p. 11).
} 
Essa intervenção estatal surgiu como forma de pressão do Estado sobre a economia para preservar o regime de livre concorrência, visando reprimir o abuso do poder econômico, mas, atualmente, ampliam-se os objetivos da regulação, mediante a qual se incluem o disciplinamento de preços, consumo, poupança e investimentos (SABBAG, 2014).

Como toda atuação do Estado, a intervenção na economia deve seguir preceitos constitucionais, que, no caso, são os princípios da ordem econômica, a qual é fundada na valorização do trabalho humano e na livre iniciativa, e, como ressalta Derani (2008), tem por fim constitucional "assegurar a todos existência digna, conforme os ditames da justiça social” (DERANI, 2008, p. 229), referindose à disposição expressa do art. 170 da Constituição Federal.

Os princípios gerais da atividade econômica são a soberania nacional, a propriedade privada, a função social da propriedade, a livre concorrência, a defesa do consumidor, a redução das desigualdades regionais e sociais, a busca do pleno emprego, o tratamento favorecido para empresas de pequeno e médio porte e a defesa do meio ambiente, inclusive com tratamento diferenciado para produtos e serviços, bem como seus processos de elaboração e prestação, conforme o impacto ambiental por eles gerados (BRASIL, [1988] 2016).

Nesse campo, a tributação atua como indutor de comportamentos, pois pode privilegiar determinados agentes econômicos por meio de reduções ou isenções de tributo(s) ou, ainda, preferindo-os para obtenção de crédito e até mesmo oferta de subsídios, com a finalidade de estimular a prática de determinada conduta ou abstenção de determinado comportamento socialmente nocivo. O que o faz, com o emprego da extrafiscalidade tributária (STELO; MURARO, 2009).

\section{EXTRAFISCALIDADE TRIBUTÁRIA}

A tributação tem em sua essência a finalidade eminentemente fiscal, ou seja, tem o objetivo de arrecadar recursos materiais para os cofres do Estado. No entanto, por vezes os tributos são utilizados com fins diversos da mera arrecadação de valores, ocasião em que terão finalidade extrafiscal.

A tributação extrafiscal, segundo Carvalho (2013), baseia-se na aplicação de mecanismos jurídicos para alcance de objetivos que devem prevalecer sobre a arrecadação de recursos monetários, mas, ressalta que tais pretensões tributárias extrafiscais devem observar os exatos limites constitucionais imponíveis ao exercício do Poder de Tributar (CARVALHO, 2013).

A extrafiscalidade tributária é um importante instrumento inibidor de condutas socialmente reprováveis e indutor de comportamentos salutares, 
cabendo citar sua prevalência até mesmo sobre um dos princípios limitadores do Poder de Tributar, o princípio da capacidade contributiva (BRASIL, [1988] 2016). O que defende Sabbag (2014), explicitando a possibilidade dada ao Estado de priorizar o alcance de finalidades indutoras, como a realização da função social da propriedade e a proteção ao meio ambiente, em detrimento da capacidade econômica dos contribuintes.

Evidente que a tributação extrafiscal não poderá retirar do contribuinte sua capacidade econômica para prover o mínimo existencial, pois teria nítido caráter confiscatório e não regulador ou indutor de condutas benéficas à sociedade.

Ressaltam Buffon e Alexandrino (2014), a dupla finalidade e dupla razão de existir do sistema tributário, a obtenção de recursos para a manutenção do Estado - fiscalidade - e o alcance do verdadeiro fim estatal, a garantia da efetivação dos direitos fundamentais dos cidadãos, "o que significa falar de extrafiscalidade, considerando-a como os objetivos valorativos da tributação" (GOUVÊEA, 2005 apud BUFFON; ALEXANDRINO, 2014, p. 4), com vistas à redução de desigualdades sociais e consecução dos objetivos constitucionais (SABBAG, 2014).

As políticas tributárias devem mirar os fins do Estado, com vistas a alcançar o desenvolvimento duradouro, fomentando "comportamentos virtuosos, inibindo os impactos nocivos não precificados pelos agentes econômicos, evitando, dessa forma, condutas antijurídicas e danosas" (TOMKOWSKI, 2016, p. 491). Esse autor também salienta que estas políticas não devem possuir caráter sancionatório, tampouco meramente arrecadatório, mas indutor, respeitando os critérios de sustentabilidade, visando efetivar os objetivos constitucionais do Estado (TOMKOWSKI, 2016).

A função extrafiscal do tributo permite o aumento da carga tributária ou a transformação de condutas consideradas socialmente indesejadas, para fomentar aquelas que almejam equilibrar as atividades econômicas com os recursos naturais explorados (FERREIRA, 2015).

A extrafiscalidade na tributação pode aparecer de várias formas, seja com finalidade de interferir na economia, "sobretaxando" a saída da moeda para o exterior e a entrada de produtos importados, seja almejando preservar a saúde pública, majorando a tributação sobre produtos nocivos, como o cigarro e as bebidas alcoólicas, ou ainda buscar a proteção do meio ambiente.

Nesse sentido, possui aptidão para induzir comportamentos de determinados setores da economia, levando seus agentes à prática de condutas orientadas para a proteção ambiental, isto sem perder sua importância econômica, é o que Stelo e Muraro (2009, p. 49) chamam de uma "intervenção econômica em sentido estrito por indução". 
Por fim, vale mencionar uma dupla conceituação da extrafiscalidade defendida por Caliendo (2016), a qual pode ser definida, pelo "conceito restritivo", como um fenômeno autorizador da competência tributária ordenadora, interventiva ou redistributiva, enquanto que, pelo conceito amplo, poderá compreender a incorporação dos efeitos extrafiscais das normas tributárias na própria natureza dos tributos; o que, para ele, neste último, daria margem a ampliação da ação indutora do Estado para além dos limites constitucionais, tendo a Constituição Federal adotado a "interpretação restritiva" do conceito de extrafiscalidade (CALIENDO, 2016).

Caliendo (2016) ainda aponta três elementos caracterizadores da extrafiscalidade tributária no Brasil, que são: a) o fim constitucionalpretendido, expressa previsão constitucional que visa alcançar as "finalidades da Ordem Constitucional ou Social (família, cultura, meio ambiente etc.)" (CALIENDO, 2016, p. 197); b) o meio utilizado; e c) a técnica adotada. Defende, contudo, que a natureza da norma extrafiscal deriva da finalidade constitucional e não da destinação dos recursos ou técnicas utilizadas, podendo ter natureza econômica, quando almeja realizar os objetivos constitucionais previstos na ordem econômica, ambiental, quando pretende realizar os objetivos para um meio ambiente ecologicamente equilibrado, entre outros (CALIENDO, 2016).

O desenvolvimento da temática relativa à extrafiscalidade ambiental exige o delineamento metodológico utilizado para alcançar o estado do conhecimento científico a respeito do tema no Brasil, razão pela qual se declina, a seguir, os métodos empregados nesta pesquisa inventariante e, ao fim, a consolidação do conhecimento a respeito do tema.

\section{METODOLOGIA}

A presente pesquisa pautou-se pelo levantamento e avaliação da produção científica (FERREIRA, 2002) nacional, publicada na última década em periódicos classificados pela Capes, nas áreas das Ciências Ambientais e do Direito, por retratarem afinação e consolidação do conhecimento a respeito do tema, seu avanço e refinamento científico na atualidade.

Baseando-se nesse critério, foram excluídos os trabalhos e os resumos publicados em anais, congressos e eventos, bem como os artigos publicados em revistas não classificadas pela Capes. Também foram excluídas as monografias, dissertações e teses, por expressaram o conhecimento acadêmico em construção.

Pleiteou-se inventariar essa produção, suas tendências e ênfases, para responder as questões de "quando", "onde" e "quem" produziu pesquisas 
relacionadas à extrafiscalidade ambiental no período supracitado, com foco na legislação, doutrina e jurisprudência nacionais, buscando ainda evidenciar sobre "O quê" e "o como" o tema é tratado nos trabalhos inventariados (FERREIRA, 2002).

Para levantamento dos artigos, utilizou-se como instrumento de seleção a conjugação dos termos "extrafiscalidade" "ambiental", o qual foi aplicado em mecanismos de buscas institucionais sobre produção científica. A periodização da pesquisa abrangeu 2007 a 2016, resultando 26 (vinte e seis) artigos publicados em 22 (vinte e dois) periódicos, cuja quantidade de publicações segue ilustrada no Gráfico 1, considerando o ano em que as pesquisas foram publicadas.

Gráfico 1 - Publicações inventariadas por ano de publicação

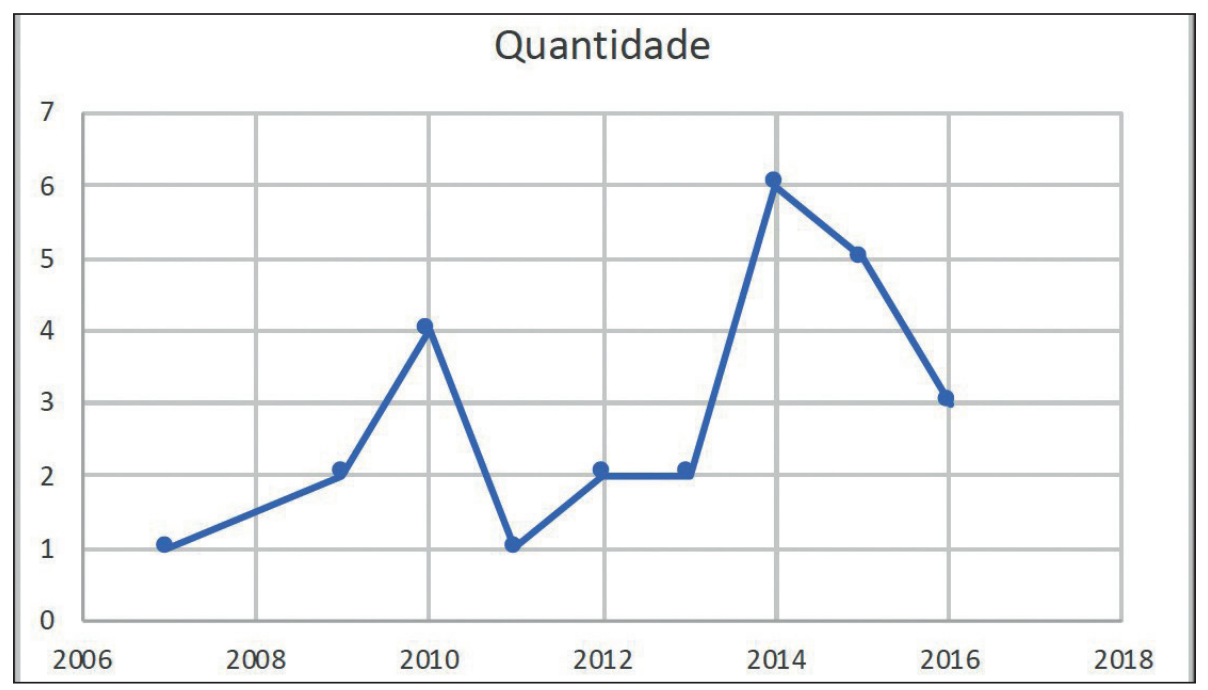

Fonte: elaborado pelos autores.

Nota-se que houve um aumento no número de publicações dentro do período avaliado nos anos de 2010 e 2014, atingindo o ápice de pesquisas publicadas sobre a temática no ano de 2014, que foi sucedido de queda gradual nos anos subsequentes, 2015 e 2016.

Dentre as publicações cumularam pesquisas publicadas as revistas "Revista Argumentum", com duas publicações no ano de 2009, "Revista do Direito Público", com duas publicações nos anos 2010 e 2011, "Revista Eletrônica Direito e Política", com duas publicações nos anos de 2007 e 2010 e a "Revista Jurídica Luso-Brasileira", também com duas publicações, ambas no ano de 2016.

Por se tratar de pesquisa inventariante, levando-se em conta a pertinência temática e o escopo da pesquisa, os artigos científicos que a lastrearam foram distribuídos nos Quadros 1 e 2. 
O Quadro 1 contém os artigos citados no corpo desta pesquisa, bem como seus autores, título da pesquisa, ano de publicação, e seguem referenciados ao final desta, vez que foram citados na retratação do estado do conhecimento atual sobre a extrafiscalidade ambiental.

Quadro 1 - Publicações citadas na pesquisa

\begin{tabular}{|l|l|c|}
\hline \multicolumn{1}{|c|}{ Autor(es) } & \multicolumn{1}{|c|}{ Artigo } & Data \\
\hline $\begin{array}{l}\text { BANNWART, C.; } \\
\text { TERASACA, C. }\end{array}$ & $\begin{array}{l}\text { Intervenção do Estado na ordem econômica por meio } \\
\text { da tributação sobre as emissões de carbono com a } \\
\text { finalidade de tutela do meio ambiente e promoção do } \\
\text { desenvolvimento sustentável }\end{array}$ & 2014 \\
\hline $\begin{array}{l}\text { BASSOLI, M. K.; } \\
\text { ALMEIDA, I. F. de }\end{array}$ & $\begin{array}{l}\text { Intervenção do estado sobre o domínio econômico por } \\
\text { meio da extrafiscalidade em prol da segurança ambiental }\end{array}$ & 2011 \\
\hline $\begin{array}{l}\text { BLANCHET, L. } \\
\text { A.; OLIVEIRA, E. } \\
\text { L. de }\end{array}$ & $\begin{array}{l}\text { Tributação da Energia no Brasil: necessidade de uma } \\
\text { preocupação constitucional extrafiscal e ambiental }\end{array}$ & 2014 \\
\hline $\begin{array}{l}\text { BUFFON, M.; } \\
\text { ALEXANDRINO, } \\
\text { C. S. }\end{array}$ & $\begin{array}{l}\text { A extrafiscalidade como instrumento de proteção do } \\
\text { meio ambiente ecologicamente equilibrado. }\end{array}$ & 2014 \\
\hline CALIENDO, P. & $\begin{array}{l}\text { Tributação e ordem econômica: os tributos podem ser } \\
\text { utilizados como instrumentos de indução econômica? }\end{array}$ & 2016 \\
\hline FERREIRA, C. I. & $\begin{array}{l}\text { Proteção ambiental e seus reflexos econômicos no } \\
\text { direito tributário brasileiro }\end{array}$ & 2015 \\
\hline HUNING, L. & $\begin{array}{l}\text { A extrafiscalidade ambiental como um instrumento de } \\
\text { justiça socioambiental do Estado brasileiro }\end{array}$ & 2016 \\
\hline $\begin{array}{l}\text { ISERHARDT, P. } \\
\text { M. }\end{array}$ & $\begin{array}{l}\text { O incentivo fiscal empresarial como forma de proteção } \\
\text { ao meio ambiente. }\end{array}$ & 2012 \\
\hline MANSANO, J. & $\begin{array}{l}\text { A tributação ambiental como instrumento de } \\
\text { desenvolvimento econômico sustentável }\end{array}$ & 2010 \\
\hline TOMKOWSKI, F. & $\begin{array}{l}\text { A tributação extrafiscal e as teorias da decisão como } \\
\text { indutores de comportamentos sustentáveis }\end{array}$ & 2016 \\
\hline
\end{tabular}

Fonte: elaborado pelos autores.

Dentro do escopo da presente pesquisa e da metodologia aplicada, também foram localizadas as publicações relacionadas no Quadro 2, as quais guardam relação com a extrafiscalidade ambiental e foram consultadas para dar concretude ao tema, visando a obtenção do "estado da arte" (FERREIRA, 2002). O Quadro 2 descreve a autoria, o título dos artigos, o periódico de publicação e o ano, incluindo ainda apertada síntese, de modo a proporcionar a rápida consulta à temática das publicações. 
Quadro 2 - Publicações consultadas

\begin{tabular}{|c|c|c|c|}
\hline Autor(es) & Artigo & Revista & Data \\
\hline CALIENDO, P. & $\begin{array}{c}\text { A extrafiscalidade } \\
\text { como instrumento de } \\
\text { implementação dos } \\
\text { direitos fundamentais } \\
\text { sociais no Brasil }\end{array}$ & $\begin{array}{c}\text { Revista Jurídica } \\
\text { do Cesuca }\end{array}$ & 2014 \\
\hline
\end{tabular}

Resumo: Trata da tributação com finalidades extrafiscais como instrumento de implementação dos direitos sociais no Brasil, do papel do Estado como ordenador, interventor e promotor dos direitos fundamentais no Estado Democrático de Direito, por meio do uso de instrumentos tributários. Aborda as funções do estado como promotor de direitos fundamentais prestacionais e corretor de falhas de mercado.

\section{CUNHA, D. S.} A.; MARTINEZ, A. L.; NOSSA, V.

\section{Incentivos fiscais verdes e tributação} extrafiscal: estudo sobre o IPTU verde no município de Vila Velha (ES) comparativamente a outros municípios

\section{Revista Razão \\ Contábil \& \\ Finanças}

2013

Resumo: Aborda sobre os incentivos fiscais verdes, inseridos no contexto de desenvolvimento sustentável, com a adoção de sanções premiais. Aborda os conceitos de finalidade extrafiscal da tributação, responsabilidade social e incentivos fiscais, especificamente de incentivos verdes, existentes no Município de Vila Velha/ES, foco no Imposto Sobre a Propriedade Predial e Territorial Urbana (IPTU).

\begin{tabular}{|l|c|c|c|}
\hline $\begin{array}{l}\text { GLASENAPP, } \\
\text { M. C. }\end{array}$ & $\begin{array}{c}\text { Controle do equilíbrio } \\
\text { do meio ambiente pela } \\
\text { ação tributária }\end{array}$ & $\begin{array}{c}\text { Revista } \\
\text { Eletrônica } \\
\text { Direito e Política }\end{array}$ & 2007 \\
\hline
\end{tabular}

Resumo: Trata de estudo sobre a existência de uma intersecção do regime tributário com a proteção do meio ambiente, demonstrado um controle do equilíbrio ambiental, mediante a chamada tributação ativa e passiva.

\begin{tabular}{|l|c|c|c|}
\hline GORON, H. S. & $\begin{array}{c}\text { As condutas "verdes" e } \\
\text { a finalidade extrafiscal } \\
\text { da tributação }\end{array}$ & $\begin{array}{c}\text { Revista } \\
\text { Síntese Direito } \\
\text { Ambiental }\end{array}$ & 2014 \\
\hline Resulent
\end{tabular}

Resumo: Analisa o tema da concessão de incentivos fiscais às condutas que, de algum modo, protegem o meio ambiente. Estuda a finalidade extrafiscal dos tributos como forma de induzir condutas ecologicamente desejadas e as espécies de incentivos fiscais passíveis de utilização. Aborda a necessária observação das responsabilidades dos agentes públicos e o orçamento dos estatais.

LENGLER, C.; MENDES, C.

A. B.

\section{O financiamento} do investimento público no sistema de drenagem urbana de águas pluviais no Brasil
2015 
\begin{tabular}{|l}
\hline Resumo: Discute a recuperação total ou parcial do investimento em obras públicas, \\
à luz das peculiaridades do sistema tributário brasileiro em vigor, no qual a taxa de \\
drenagem somente pode financiar serviços de operação e manutenção do sistema. Para \\
o investimento, deve-se utilizar a contribuição de melhoria, que passa a ser obrigatória \\
quando resulte valorização imobiliária. Os resultados evidenciam que a contribuição de \\
melhoria não possui caráter de extrafiscalidade ambiental, pois não cobra do verdadeiro \\
poluidor o dano a que deu causa.
\end{tabular}

Resumo: Faz análise acerca da energia eólica no Brasil, da possibilidade de implantação, dos impactos socioambientais, econômicos e da sua escolha como matriz energética alternativa. Todos estes aspectos são verificados para se enfrentar a crise energética e as alterações climáticas provenientes da emissão de gases do efeito estufa. Por fim, aponta o compromisso do Estado em uma solução para o problema e a necessidade de adoção de incentivos fiscais para se viabilizar empreendimentos no setor.

LIMA, L. A.; MIGUEL, L. C.
A função

socioambiental do IPTU e do ITR
Cadernos de

Direito
2012

Resumo: Estuda a função socioambiental do Imposto Predial Territorial Urbano (IPTU) e do Imposto Territorial Rural (ITR), desvendando suas correspondentes benesses em favor da estruturação de um modelo de desenvolvimento socialmente mais justo e sustentável do meio ambiente urbano e rural.

\begin{tabular}{|l|c|c|c|}
\hline $\begin{array}{l}\text { MAGANHINI, } \\
\text { T. B. }\end{array}$ & $\begin{array}{c}\text { Benefícios fiscais } \\
\text { como conduta indutora } \\
\text { do desenvolvimento } \\
\text { sustentável }\end{array}$ & $\begin{array}{c}\text { Revista do Direito } \\
\text { Público }\end{array}$ & 2010 \\
\hline
\end{tabular}

Resumo: Trata dos instrumentos econômicos que o Estado pode empregar na realização do desenvolvimento sustentável. Destaca a importância da extrafiscalidade ambiental para encontrar o ponto de equilíbrio entre o desenvolvimento econômico e o meio ambiente, por meio dos incentivos fiscais indutores de condutas ambientalmente corretas por parte dos empresários e do Estado.

\begin{tabular}{l|c|c}
$\begin{array}{l}\text { MANTOVANI, } \\
\text { S. M. }\end{array}$ & $\begin{array}{c}\text { A viabilidade da } \\
\text { extrafiscalidade } \\
\text { ambiental no âmbito } \\
\text { municipal }\end{array}$ & $\begin{array}{c}\text { Revista } \\
\text { Argumentum - } \\
\text { UNIMAR }\end{array}$ \\
\hline
\end{tabular}

Resumo: Reflete sobre as formas de extrafiscalidade ambiental no âmbito municipal, como forma de política de proteção ambiental. Menciona a Lei de Responsabilidade Fiscal e o Estatuto da Cidade como meios de viabilizar os benefícios fiscais municipais. Conclui pela importância do Município em implementar as políticas públicas ambientais em conjunto com os Estados-membros, Distrito Federal e União. 


\begin{tabular}{|l|c|c|c|}
\hline MARQUES, & A validade do emprego & Revista & \\
L. N.; & da extrafiscalidade & Tributária e & \multirow{2}{*}{2014} \\
BARBOSA, P. & tributária na proteção & $\begin{array}{c}\text { de Finanças } \\
\text { Públicas }\end{array}$ & \\
G; NORONHA, & do meio ambiente & S. X. & \\
\hline
\end{tabular}

Resumo: Busca fornecer uma análise que contemple a validade jurídica da utilização da extrafiscalidade tributária como instrumento capaz de promover a preservação ambiental, apurar os limites da atividade legislativa voltada à proteção ambiental por meio do manejo da tributação, especialmente a partir da investigação da natureza do tributo e do entendimento do princípio da capacidade contributiva.

\begin{tabular}{|l|c|c|c|}
\hline $\begin{array}{l}\text { OLIVEIRA, D. } \\
\text { B. de }\end{array}$ & $\begin{array}{c}\text { "IPTU verde": uma } \\
\text { perspectiva legislativa } \\
\text { no município de } \\
\text { Pelotas }\end{array}$ & $\begin{array}{c}\text { Revista Eletrônica } \\
\text { da Faculdade } \\
\text { de Direito da } \\
\text { Universidade } \\
\text { Federa de Pelotas }\end{array}$ & 2015 \\
\hline
\end{tabular}

Resumo: Da mescla entre a questão ambiental, das competências tributárias do município e da extrafiscalidade dos tributos emerge o questionamento central: como o caráter extrafiscal do Imposto sobre a Propriedade Predial e Territorial Urbana (IPTU) pode servir de balizador de condutas ambientalmente corretas sobre o imóvel urbano. Destaca alguns aspectos relevantes sobre a extrafiscalidade ambiental na legislação Município de Pelotas.

\begin{tabular}{|c|c|c|c|}
\hline OLIVEIRA, L. & \begin{tabular}{|c|} 
Direito tributário e \\
economia: análise \\
conjunta para objetivos \\
sociais sustentáveis
\end{tabular} & $\begin{array}{l}\text { Revista do } \\
\text { Mestrado em } \\
\text { Direito UCB }\end{array}$ & 2013 \\
\hline \multicolumn{4}{|c|}{$\begin{array}{l}\text { Resumo: Questiona a função do Direito quando trata da sustentabilidade do meio } \\
\text { ambiente, dos reflexos sociais e dos impactos econômicos. Nesse quadro se nota que o } \\
\text { Direito Tributário tem um importante papel não apenas como instrumento arrecadador, } \\
\text { mas porque pode, por meio do mecanismo da extrafiscalidade indicar condutas, como } \\
\text { ferramenta indutora. }\end{array}$} \\
\hline $\begin{array}{l}\text { PERALTA, C. } \\
\text { E. }\end{array}$ & $\begin{array}{l}\text { Tributação ambiental } \\
\text { no brasil. Reflexões } \\
\text { para esverdear o } \\
\text { sistema tributário } \\
\text { brasileiro }\end{array}$ & $\begin{array}{c}\text { Revista de } \\
\text { Finanças } \\
\text { Públicas } \\
\text { Tributação e } \\
\text { Desenvolvimento }\end{array}$ & 2015 \\
\hline \multicolumn{4}{|c|}{$\begin{array}{l}\text { Resumo: Realiza uma análise sobre o papel que pode desempenhar o tributo, atra- } \\
\text { vés da extrafiscalidade, como um dos instrumentos para promover o desenvolvimento } \\
\text { sustentável. Concretamente, o trabalho examina a introdução da variável ambiental no } \\
\text { sistema tributário Brasileiro. }\end{array}$} \\
\hline $\begin{array}{l}\text { PIACENTINI, } \\
\text { A. L. S.; } \\
\text { ALMEIDA, F. } \\
\text { M.; PEDRO } \\
\text { FILHO, F. de S. }\end{array}$ & $\begin{array}{l}\text { Estudo epistemológico } \\
\text { sobre práticas } \\
\text { extrafiscais de gestão } \\
\text { urbana sustentável. }\end{array}$ & $\begin{array}{c}\text { Revista } \\
\text { InterScience Place }\end{array}$ & 2015 \\
\hline
\end{tabular}


Resumo: Trata sobre a produção de normas legais no Brasil denominadas tributação verde, especificamente acerca do Imposto sobre a Propriedade Predial e Territorial Urbana (IPTU Verde). Como resultado, constata que as normas são instrumentos com objetivos conceituais semelhantes; que a maior ênfase às dimensões ambientais e econômicas distorce a essência do instrumento. Conclui que as normatizações têm replicado de forma isomórfica uma concepção de sustentabilidade divergente do proposto pela teoria. Em decorrência disso é possível afirmar que os cidadãos são impelidos a comportamentos que visam prioritariamente seu benefício econômico, prestando um serviço contextualizado e desconexo.

\begin{tabular}{|l|c|c|}
\hline SALLES, A. F. & $\begin{array}{c}\text { Evolução do direito } \\
\text { do meio ambiente e } \\
\text { tributação }\end{array}$ & $\begin{array}{c}\text { Revista } \\
\text { Eletrônica } \\
\text { Direito e Política }\end{array}$ \\
\hline
\end{tabular}

2010

Resumo: Aborda a evolução do Direito Ambiental sob distintos enfoques. Diante da constatação de que as técnicas de repressão são ineficazes para a proteção dos bens ambientais, uma vez que atuam quando o dano já está consumado, passaram-se a desenvolver instrumentos de prevenção, participação, internalização de custos, proteção integral e de ambientalização do direito. Dentro dessas novas tendências, a tributação ambiental surge como um instrumento bastante eficaz. Os países desenvolvidos já vêm utilizando a tributação ambiental como forma de incentivar condutas sustentáveis com bastante vigor e, atualmente, também os países em desenvolvimento vêm adotando iniciativas interessantes nesse sentido.

\section{SILVA, L. R.}

F. da

\section{Extrafiscalidade,} incentivos fiscais:

ausência de
igualdade e justiça
no desenvolvimento
regional

\begin{tabular}{|c|} 
Revista \\
Argumentum - \\
UNIMAR
\end{tabular}

Resumo: Faz reflexões acerca da intervenção estatal sobre a economia, com aplicação de incentivo fiscal para desenvolvimento regional acompanhado de sua proposta de melhores expectativas de desenvolvimento. Aponta a falta de eficiência na aplicação de incentivos fiscais, por gerar distorções que acabam por não conjugar os objetivos econômicos e sociais do instituto, diante da prevalência ao aspecto econômico, ausente o alcance da igualdade tributária e do bem comum. Afirma que faz-se necessária melhor conciliação entre resultados de desenvolvimento econômico e justiça tributária para que os objetivos do incentivo fiscal se concretizem.

Fonte: elaborado pelos autores.

Os artigos selecionados foram analisados em conjunto a doutrina e a legislação, para consolidar o estado do conhecimento da função extrafiscal da tributação com vistas à proteção ambiental - extrafiscalidade ambiental -, com intuito de criar subsídios à adoção de políticas tributárias pautadas na proteção do meio ambiente, por meio da extrafiscalidade tributária. 


\section{EXTRAFISCALIDADE AMBIENTAL}

É certo que a defesa e a preservação do meio ambiente ecologicamente equilibrado são deveres do Estado e direito fundamental assegurado a todos os indivíduos pela Constituição Federal de 1988 (BRASIL, [1988] 2016)², e, diante da finitude dos recursos naturais e utilização muitas vezes descontrolada, deve o Estado valer-se não só de instrumentos de coerção, mas também de instrumentos econômicos para a tutela do meio ambiente.

Nesse sentido, uma vez caracterizada a escassez dos recursos naturais, é possível aferir-lhes um valor e, por consequência, tratá-los a partir de mecanismos de mercado, proporcionando a valoração e a remuneração aos que preservam os chamados serviços ambientais e, por outro lado, cobrando pelo uso dos recursos - princípios do usuário pagador e do poluidor pagador.

Nusdeo (2006, p. 358) afirma que a não imposição dessa precificação acarreta "trocas involuntárias de custos e benefícios" não captadas pelo mercado, que acabam sendo suportadas pela sociedade. Salienta ainda a significativa frequência com que isso ocorre, pois o mercado "costuma ser incapaz de fixar e incentivar o pagamento por preços relativos ao uso ou à preservação dos recursos ambientais" (NUSDEO, 2006, p. 359).

Apesar da proteção do meio ambiente ser dever de todos, ao Estado compete intervir na economia, conforme preceitua o artigo 170, inciso VI, da Constituição Federal, para assegurar "tratamento diferenciado conforme o impacto ambiental dos produtos e serviços e de seus processos de elaboração e prestação" (BRASIL, [1988] 2016, p. 109), verdadeiro poder-dever, e, para tanto, poderá valer-se inclusive do Sistema Tributário Nacional.

Ao Direito Tributário compete orientar a atividade econômica para reverter benefícios à coletividade, o que, quando ocorre, retira da tributação seu caráter precipuamente fiscal, de obtenção de recursos, e lhe dá feição de instrumento interventivo no desenvolvimento econômico e repartição de recursos, tornando mais eficazes os direitos fundamentais econômicos, culturais e sociais (BUFFON; ALEXANDRINO, 2014).

É inegável que para a consecução dos objetivos do Estado este carece de recursos, os quais derivam precipuamente do sistema tributário. Todavia, este sistema pode conter mecanismos capazes de induzir condutas benéficas de proteção ecológica, pela chamada extrafiscalidade ambiental. Blanchet e

\footnotetext{
"Art. 225. Todos têm direito ao meio ambiente ecologicamente equilibrado, bem de uso comum do povo e essencial à sadia qualidade de vida, impondo-se ao Poder Público e à coletividade o dever de defendê-lo e preservá-lo para as presentes e futuras gerações” (BRASIL, [1988] 2016, p. 131).
} 
Oliveira (2014) apontam a necessidade premente de uma reforma tributária nacional com preocupação ambiental, a qual ganha legitimidade pelo aspecto ambiental, decorrente de preceitos constitucionais e experiências internacionais, mas também pelo que chamam de duplo dividendo: resultados financeiros e ambientais (BLANCHET; OLIVEIRA, 2014).

Ainda como resultado da pesquisa, é possível encontrar autores que defendem a tributação ambiental como meio capaz de promover a proteção ambiental, induzindo comportamentos por meio da extrafiscalidade, gravando atividades degradantes ao meio ambiente de forma mais rígida e desonerando ou incentivando aquelas condutas tendentes à proteção ecológica (BLANCHET; OLIVEIRA, 2014).

De fato, o sistema tributário nacional possui mecanismos de cunho social, notadamente voltados à tutela de direitos fundamentais de terceira dimensão, que visam incentivar benéficas atividades, como aquelas voltadas para a redução da degradação ambiental, corroboram Buffon e Alexandrino (2014).

A extrafiscalidade ambiental é um dos mecanismos eficientes para a preservação do meio ambiente, pois proporciona ao Estado o direito de agir para desestimular condutas poluidoras, mas também o dever de estimular condutas protetoras ao meio, podendo ser utilizada como um "instrumento de transformação social” em prol do equilíbrio ambiental (HUNING, 2016).

Ao instituir tributos ambientais é possível induzir o comportamento dos sujeitos passivos, com vistas à proteção do ecossistema, forçando-os a considerar as consequências resultantes de suas condutas, frente aos possíveis reflexos, perda patrimonial (pagamento majorado de tributos decorrentes de condutas poluentes) e credibilidade comercial (relacionada à imagem da empresa a seus consumidores, que exigem a busca por alternativas sustentáveis de produção), fomentando, assim, a procura por tecnologias mais modernas e menos poluentes, o que, para Bannwart e Terasaca (2014), concretiza o desenvolvimento sustentável.

Ressalta Mansano (2010) que o objetivo da tributação ambiental não é a criação de tributos novos, mas o uso de instrumentos tributários que estimulem a implantação de processos e técnicas para a defesa do meio ambiente, tais como a aplicação de incentivos fiscais para estimular comportamentos, como o uso de dispositivos antipoluidores, visando desestimular a circulação e consumo de bens "ecologicamente incorretos", para promoção do equilíbrio ecológico (MANSANO, 2010).

$\mathrm{Na}$ atual conjuntura, a implementação de incentivos fiscais ambientais supressão ou redução dos tributos, derivadas de comportamentos protecionistas ao meio ambiente - pode mostrar-se um mecanismo eficaz de proteção ambiental, 
em face da elevada carga tributária percebida pela classe empresarial. Corrobora Iserhardt (2012), exemplificando algumas espécies de benefícios fiscais, como a depreciação acelerada, a dedução total ou parcial de custos, a concessão de créditos fiscais e as isenções fiscais (ISERHARDT, 2012).

Há inclusive proposição de introdução da extrafiscalidade ambiental no imposto sobre produtos industrializados (IPI), com a inserção de dispositivo constitucional que prevê a aplicação de alíquotas diferenciadas em razão da responsabilidade socioambiental das atividades desempenhadas pelo contribuinte, pautando a tributação na seletividade socioambiental.

A seletividade é um princípio de observância obrigatória no imposto incidente sobre os produtos industrializados, e analisa a essencialidade destes ao ser humano para aplicação da tributação. Ao passo que a seletividade socioambiental propõe a análise da essencialidade ambiental dos produtos industrializados, aferindo os níveis de poluição de tais produtos, como ressaltam Bassoli e Almeida (2011), graduando as alíquotas do imposto de modo a estimular o fabrico e o comércio de produtos não poluentes ou degradantes (FERREIRA, 2015).

Dentre as diferentes possibilidades de atuação da tributação em prol da proteção do meio ambiente, a respeito de incentivos e benefícios fiscais, exemplifica Carolina Ferreira (2015) um mecanismo já implementado no Brasil, que são os créditos de carbono ${ }^{3}$, voltado para a redução da emissão dos gases do efeito estufa. Tal mecanismo exime investidores de projetos associados ao mercado de carbono do pagamento de Imposto de Renda e demais contribuições sociais (FERREIRA, 2015).

Embora tal afirmação ainda apresente divergência, por não existir legislação específica estabelecendo o tratamento tributário do mercado de carbono, há respaldo constitucional para afirmar que a comercialização ao exterior de créditos dessa natureza, por se tratar de exportação, afasta a incidência de determinados tributos federais, tais como as contribuições sociais, por possuírem imunidade tributária ${ }^{4}$.

O mercado de créditos de carbono surgiu como um mecanismo de flexibilização do Protocolo de Kyoto, com o objetivo de atingir as metas de redução das emissões de gases de efeito estufa (GEE) pelos países que o ratificaram. Assim, criaram-se os mecanismos de desenvolvimento limpo (MDL) que permitem a comercialização de créditos de carbono, denominados redução certificadas de emissões (RCE), que sejam resultado de projetos desenvolvidos nos países em desenvolvimento que ratificaram tal Protocolo, estando o Brasil entre eles. O cálculo é baseado em toneladas de dióxido de carbono equivalente e cada tonelada reduzida ou removida da atmosfera corresponde a uma unidade emitida pelo Conselho Executivo do MDL.

4 "Art. 149. [...] \ $2^{\circ}$ As contribuições sociais e de intervenção no domínio econômico de que trata o caput deste artigo: I - não incidirão sobre as receitas decorrentes de exportação" (BRASIL, [1988] 2016, p. 94, grifo do autor). 
No tocante à incidência tributária do imposto sobre a renda, as discussões se intensificam, mas é possível afirmar que a mera expedição da redução certificada de emissões (RCE) não desencadeia fato gerador do imposto de renda, por se tratar de mera incorporação do ativo ao patrimônio do titular. Já no que tange à comercialização da RCE, os valores resultantes dessa transação integrarão a base de cálculo do IR e o ganho de capital será aferido pela apuração da diferença entre os custos de sua aquisição e os valores obtidos na transferência (KEMPFER, 2016).

\section{CONSIDERAÇÕES FINAIS}

No intuito de contribuir com o fomento das discussões envolvendo a utilização de mecanismos tributários para proteção do meio ambiente, buscou-se destacar a importância dessa modalidade de estudo do tipo "estado da arte", com a finalidade de subsidiar iniciativas legislativas com foco na proteção ambiental por meio da tributação.

No tocante ao estado do conhecimento a respeito do tema, os vinte e seis trabalhos publicados e inventariados corroboraram a afirmação de que a intervenção do Estado na economia, por meio de sua atuação normativa e reguladora, para exercício de suas funções de fiscalização, incentivo e planejamento da atividade econômica, também é feita com o uso da extrafiscalidade tributária.

As discussões doutrinárias e o estado atual das pesquisas sobre a temática, uníssonos, apontam que a extrafiscalidade tributária não se trata de um mecanismo punitivo, com objetivo de aplicar sanções, pois se o fosse não coadunaria com a essência do próprio tributo, uma vez que este se aplica em estrita observância da lei e não em virtude da transgressão jurídica de uma norma.

A resposta encontrada para a problemática perseguida mostrou-se afirmativa, ou seja, é pacífico no saber científico atual que a tributação poderá ter conotação eminentemente ambiental, voltada à proteção e promoção do direito social ao meio ambiente ecologicamente equilibrado, por meio da aplicação da extrafiscalidade ambiental, coadunando com a hipótese levantada para a questão.

O "estado da arte" alcançado consolidou-se na narrativa de que esta forma de extrafiscalidade poderá ser adotada na tributação de diferentes maneiras, não só com a majoração da tributação para atividades ambientalmente nocivas, mas também com o emprego de benefícios e incentivos fiscais, como forma indutora do comportamento dos particulares em prol da proteção ambiental. 
É importante salientar que a pesquisa não pretendeu esgotar a discussão sobre a tributação ambiental, tampouco abarcar as espécies tributárias passíveis de utilização com fins extrafiscais. Assim, buscou-se apresentar a consolidação atual do conhecimento acerca da extrafiscalidade ambiental e suas possíveis aplicações jurídicas voltadas para a proteção do meio ambiente, objetivo que se alcançou.

Há enorme campo para pesquisas futuras, como no exemplo factível e eficiente de estímulo a condutas ambientalmente protetivas que são os projetos relacionados ao mercado de carbono, pois podem eximir seus responsáveis (pessoas físicas ou jurídicas) do pagamento de determinados tributos, notadamente quando as operações decorrem da comercialização dos créditos de carbono ao exterior.

Todo esforço humano destinado à proteção ambiental deve ser objeto de estudo, pois invariavelmente reverberará de forma positiva para a própria sociedade, sendo a extrafiscalidade ambiental um importante instrumento estatal de fomento a condutas ambientalmente benéficas, que apresenta congruência com o ordenamento jurídico brasileiro.

\section{REFERÊNCIAS}

ALBUQUERQUE, R. C. de. A reforma tributária ecológica alemã. Revista da Faculdade de Direito, São Paulo, v. 98, p. 137-156, jan. 2003. Disponível em: http://www.revistas.usp.br/rfdusp. Acesso em: 21 dez. 2016.

BANNWART, C.; TERASACA, C. Intervenção do Estado na ordem econômica por meio da tributação sobre as emissões de carbono com a finalidade de tutela do meio ambiente e promoção do desenvolvimento sustentável. Scientia iuris, Londrina, v. 18, n. 1, p. 61-90, jul. 2014. Disponível em: http://www.uel.br/ revistas/uel/index.php/iuris. Acesso em: 02 nov. 2016.

BASSOLI, M. K.; ALMEIDA, I. F. de. Intervenção do estado sobre o domínio econômico por meio da extrafiscalidade em prol da segurança ambiental. Revista do Direito Público, Londrina, v. 6, n. 1, p. 247-268, jan./abr. 2011. Disponível em: http://www.uel.br/revistas/uel/index.php/direitopub. Acesso em: 10 fev. 2017.

BLANCHET, L. A.; OLIVEIRA, E. L. de. Tributação da energia no Brasil: necessidade de uma preocupação constitucional extrafiscal e ambiental. Sequência: Estudos Jurídicos e Políticos, Florianópolis, v. 35, n. 68, p. 159 188, jun. 2014. Disponível em: https://periodicos.ufsc.br/index.php/sequencia. Acesso em: 02 nov. 2016. 
BRASIL. Constituição da República Federativa do Brasil de 1988. Brasília, DF: Senado Federal, Coordenação de Edições Técnicas, [1988] 2016. Disponível em: https://www2.senado.leg.br/bdsf/bitstream/handle/id/518231/CF88_Livro _EC91_2016.pdf. Acesso em: 03 nov. 2016.

BUFFON, M.; ALEXANDRINO, C. S. A extrafiscalidade como instrumento de proteção do meio ambiente ecologicamente equilibrado. Planeta Amazônia: Revista Internacional de Direito Ambiental e Políticas Públicas, Macapá, n. 6, p. 01-11, 2014. Disponível em: http://periodicos.unifap.br/index.php/ planeta. Acesso em: 02 dez. 2016.

CALIENDO, P. Tributação e ordem econômica: os tributos podem ser utilizados como instrumentos de indução econômica? Revista Direitos Fundamentais \& Democracia, Curitiba, v. 20, n. 20, p. 193-234, jul./dez. 2016. Disponível em: http://revistaeletronicardfd.unibrasil.com.br. Acesso em: 10 fev. 2017.

CARVALHO, P. B. Curso de direito tributário. 25. ed. São Paulo: Saraiva, 2013.

DERANI, C. Direito Ambiental Econômico. 3. ed. São Paulo: Saraiva, 2008.

FERREIRA, C. I. Proteção ambiental e seus reflexos econômicos no direito tributário brasileiro. Revista da Faculdade de Direito da Universidade Federal de Minas Gerais, Belo Horizonte, n. 67, p. 125-149, jul./dez. 2015. Disponível em: http://www.polos.ufmg.br/revista/. Acesso em: 10 fev. 2017.

FERREIRA, N. S. A. As pesquisas denominadas "estado da arte". Educação \& Sociedade, Campinas, vol. 23, n. 79, p. 257-272, ago. 2002. Disponível em: http://www.scielo.br/pdf/es/v23n79/10857.pdf. Acesso em: 01 nov. 2016.

HUNING, L. A extrafiscalidade ambiental como um instrumento de justiça socioambiental do estado brasileiro. Revista Jurídica Luso-Brasileira, [S. l.], n. 1, p. 1147-1156, 2016. Disponível em: http://www.cidp.pt/publicacoes/ revistas/rjlb. Acesso em: 10 fev. 2017.

ISERHARDT, P. M. O incentivo fiscal empresarial como forma de proteção ao meio ambiente. Revista Eletrônica do Curso de Direito da UFSM, [ $S$. l.], v. 7, n. 2, p. 94-112, dez. 2012. Disponível em: https://periodicos.ufsm.br/ revistadireito. Acesso em: 02 nov. 2016.

KEMPFER, J. C. A tributação das operações de crédito de carbono. Revista Eletrônica Direito e Política, Itajaí, v.11, n.3, 2016. Disponível em: www. univali.br/direitoepolitica. Acesso em: 12 abr. 2017. 
MANSANO, J. A tributação ambiental como instrumento de desenvolvimento econômico sustentável. Revista Espaço Acadêmico, Maringá, v. 10, n. 114, p. 100-109, nov. 2010. Disponível em: http://www.periodicos.uem.br. Acesso em: 10 nov. 2016.

NUSDEO, A. M. O. O uso de instrumentos econômicos nas normas de proteção ambiental. Revista da Faculdade de Direito da Universidade de São Paulo, São Paulo, v. 101, n. 2, p. 357-378, jan./dez. 2006. Disponível em: http://www. revistas.usp.br/rfdusp. Acesso em: 09 jan. 2016.

SABBAG, E. M. Manual de Direito Tributário. 6. ed. Rio de Janeiro; São Paulo: Editora Saraiva, 2014.

SILVA, J. A. da. Curso de Direito Constitucional Positivo. 26. ed. São Paulo: Editora Malheiros, 2006.

STELO, G.; MURARO, L. G. Política tributária e meio ambiente. Brasília: OAB Editora, 2009.

TOMKOWSKI, F. A tributação extrafiscal e as teorias da decisão como indutores de comportamentos sustentáveis. Revista Jurídica Luso-Brasileira, [S. l.], n. 2, p. 483-501, 2016. Disponível em: http://www.cidp.pt/publicacoes/revistas/rjl. Acesso em: 10 fev. 2017. 
